\title{
Concepções alternativas da temática de Terra como Corpo Cósmico de alunos em uma escola de educação profissional
}

\author{
Nascimento, J. O. do ${ }^{1 *}$; Neide, I. G ${ }^{2}$; Gonzatti, S. E. $M^{2}$; Pereira, H. B. B ${ }^{1,3}$; Moret, M. A A $^{1,3}$ \\ 1 Programa de Modelagem Computacional, CIMATEC, Salvador, BA, Brasil. \\ 2 Universidade do Vale do Taquari, Lajeado, RS, Brasil. \\ 3 Universidade do Estado da Bahia, Salvador, Bahia, Brasil. \\ *e-mail: jeffersonascimento@gmail.com
}

\begin{abstract}
Resumo
Para investigar as concepções dos discentes em uma escola de Educação Profissional, quanto aos subsunçores necessários para as abordagens dos fenômenos astronômicos, foi elaborado primeiramente um instrumento de coleta de dados, um pré-teste semiestruturado. As respostas dos alunos foram categorizadas conforme os níveis apresentados no teste desde as ingênuas e não coerentes (conforme os atuais modelos científicos), até respostas cientificamente aceitas como corretas ou próximas delas. Diante dos resultados iniciais foi construída e apresentada uma proposta didática utilizando simulação e modelagem computacional em aulas com intervenções psicopedagógicas com o intuito de verificar indícios de aprendizagem significativa, conforme a Teoria da Aprendizagem Significativa de Ausubel (TAS), durante todo o processo de investigação (não investigado nesta pesquisa). Sendo assim, verificouse que, poucos alunos dispunham de algum conhecimento prévio necessário para a aprendizagem dos fenômenos astronômicos. Ao fim, concluímos que a maioria dos discentes não apresentaram indícios de aprendizagem significativa em relação aos conhecimentos prévios necessários ao aprendizado de fenômenos astronômico.
\end{abstract}

Palavras-chave: Fenômenos Astronômicos, Terra como corpo cósmico, Ensino de Física

\begin{abstract}
In order to investigate the students' conceptions in a Professional Education school, regarding the subsumers necessary for the approaches of the astronomical phenomena, a data collection instrument, a semi-structured pre-test, was first elaborated. Student responses were categorized according to the levels presented in the test from the naive and non-coherent (according to current scientific models) to scientifically accepted answers as correct or close to them. In view of the initial results, a didactic proposal was developed using simulation and computational modeling in classes with psychopedagogical interventions in order to verify evidence of significant learning, according to Ausubel's Significant Learning Theory (TAS), throughout the research process not investigated in this research). Thus, it was verified that, few students had some previous knowledge necessary for the learning of the astronomical phenomena.
\end{abstract}

Keywords: Astronomical Phenomena, Earth as a Cosmic Body, Physics Teaching

\section{Introdução}

As concepções alternativas podem corresponder a aprendizados significativos adquiridos pelos aprendizes, porém, com incoerências em relação a um modelo científico de um determinado fenômeno a ser estudado [1]. Este fato faz com que sejam "[...] tão resistentes à mudança conceitual" durante o processo de ensino de aprendizagem [2]. A título de exemplo, o modelo da distância como a causa do fenômeno das estações do ano, ainda é verificado nos diversos níveis de ensino, deve-se também às concepções alternativas suscitadas devido a forma da trajetória elíptica da Terra ao redor do Sol) [3]. Nesta linha de raciocínio, um dos fenômenos que corresponde a um dos conhecimentos científicos que mais se destacam em ser aprendidos de forma equivocada correspondem as estações do ano [4]. A temática de Terra como um corpo cósmico, é apresentada por Nascimento, Neide e Gonzatti [1] e Nascimento et al. [5] como sendo o conceito subsunçor 
para o aprendizado dos fenômenos astronômicos. Assim, tratar a Terra como corpo cósmico, significa abordá-la por meio de sua forma, seu campo gravitacional, seus movimentos e os fenômenos astronômicos decorrentes desses movimentos e da configuração do sistema Terra-Sol-Lua, como por exemplo, dias, noites, estações do ano, fases e eclipses lunares, ou seja, a sua interação com outros astros cósmicos [1,5]. Desta forma "[...] a Terra deve ser considerada a partir da interação gravitacional dela com o Sol, assumindo-se esse conceito como alicerce fundamental para o aprendizado dos fenômenos astronômicos" [1]. Diante do exposto, este artigo tem como objetivo apresentar alguns resultados de uma pré-teste semiestruturado que verificou os conhecimentos prévios de alunos de uma turma de PROEJA em relação a temática de Terra como corpo cósmico. O PROEJA corresponde ao Programa Nacional de Integração da Educação Profissional com a Educação Básica na modalidade de educação de jovens e adultos. A oferta do PROEJA é na forma integrada entre Educação Profissional, Ensino Médio e Educação de Jovens e Adultos, sendo direcionada apenas para pessoas maiores de 18 anos [6]. Foram analisadas as respostas de 30 alunos do PROEJA (Curso Técnico em Informática), na faixa etária entre 18 e 55 anos em uma escola de educação profissional na cidade de Belém/PA.

Este trabalho está organizado em 5 seções. $\mathrm{Na}$ segunda, apresentaremos os materiais e métodos utilizados na pesquisa. Na terceira, os resultados e as discussões. Na quarta seção, as considerações finais do presente artigo. Por último, as referências utilizadas.

\section{Materiais e Métodos}

Para investigar as concepções dos discentes quanto aos subsunçores necessários para as abordagens da temática fenômenos astronômicos, realizamos a aplicação de um instrumento de coleta de dados: o pré-teste semiestruturado com sete questões abertas e fechadas. As respostas dos alunos foram categorizadas conforme os níveis apresentados no supracitado teste. A categorização abordou desde respostas ingênuas e não coerentes com os atuais modelos científicos até respostas cientificamente aceitas como corretas ou próximas. Para as avaliações das concepções sobre Terra cósmica, foram adotados três níveis.

O nível 1 (N1) corresponde às concepções ingênuas dos alunos. O nível 2 (N2) corresponde ao nível intermediário entre as respostas ingênuas e as coerentes com os atuais modeles científicos. O nível 3 (N3) refere-se àquele em que os alunos já possuem em sua estrutura cognitiva subsunçores alicerçados nos atuais modelos científicos ou são conhecedores de informações próximas a esses modelos.

\section{Resultados}

A primeira questão, estabelecia a suposição do aluno se colocar no lugar de um astronauta, em uma nave, orbitando a Terra, para que pudesse expor a visão que ele tem sobre o formato do nosso planeta. Foi solicitado que fosse feito o desenho da Terra, com pessoas na superfície, nuvens e a chuva. A Figura 1 apresenta a resposta do Aluno $\mathrm{A6}$, categorizada como nível 1:

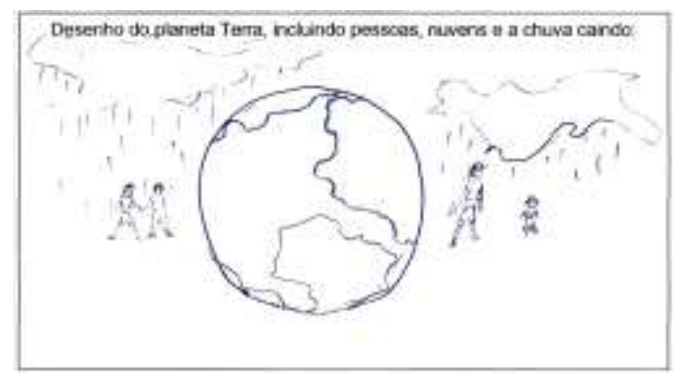

Figura 1: Resposta do Aluno A6 representando a de todos os discentes em que suas respostas foram categorizadas como Nível 1.

Os discentes desenharam pessoas caminhando ou estáticas no espaço sideral com a chuva sobre elas, enquanto passeiam. Esta situação se repete para os discentes que apresentaram duas respostas categorizadas no Nível 1 (N1). Mesmo a Terra sendo retratada de forma esférica, verifica-se que as interações gravitacionais foram ignoradas. Para o N1, Nussbaum e Novak [7] e Nardi e Carvalho [8], não há conexão entre o formato da Terra e as suas interações gravitacionais com os demais corpos. Há o estabelecimento de sentido de queda (de cima para baixo) para corpos desenhados no espaço (que 
deveriam ter sido desenhados interagindo com a Terra). Como exemplo das respostas verificas dos alunos no Nível 2 (N2), na Figura 2, apresentamos a resposta do Aluno A4. As nuvens, chuva e pessoas demonstram uma tentativa do discente, de representar uma coerência entre a forma da Terra e a interação gravitacional, mas ainda sem sucesso. Conforme Baxter [9], os alunos com essas concepções do N2 não apresentam a capacidade de argumentar, por exemplo, como seria a posição de uma pessoa no Ártico e na Antártida.

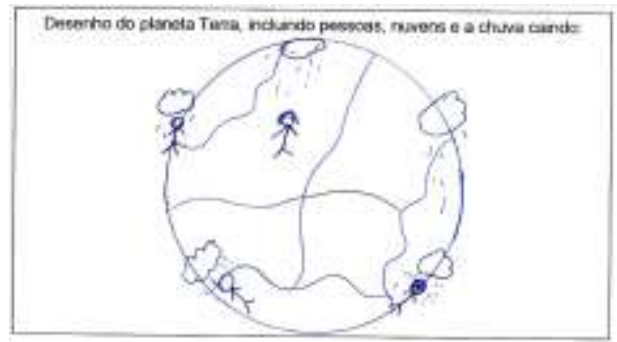

Figura 2: Resposta do Aluno A4 representando a de todos os discentes em que suas respostas foram categorizadas como Nível 2.

Conforme Figura 3, o Aluno A10 apresentou sua resposta de forma característica com o nível 3, em que a disposição dos continentes representados, as nuvens e as pessoas, são retratados de forma próxima a um modelo coerente cientificamente, devido ao fato de suas ilustrações acompanharem a curvatura da Terra.

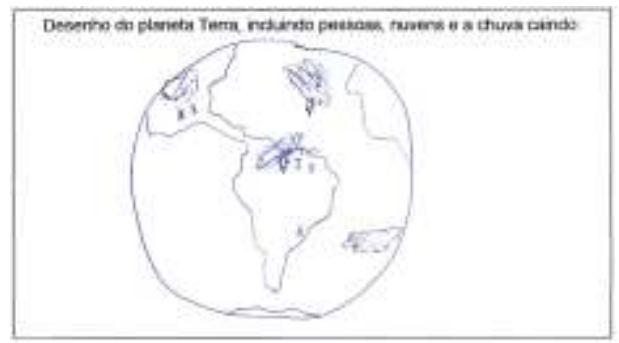

Figura 3: Resposta do Aluno A10, o único a apresentar uma resposta categorizada no N3.

No total 15 alunos apresentaram respostas categorizadas no N1, 14 no N2 e 1 aluno com resposta categorizada no N3. A segunda questão investigava as noções de Terra esférica e gravidade. Cabia ao aluno que desenhassem o copo vazio na Antártida e na segunda fase, que desenhassem o copo com água até a metade, também na Antártida. A Figura 4 apresenta a resposta do Aluno $A 18$. O discente não foi capaz de perceber $o$ fato de que os copos interagem gravitacionalmente com a Terra, não sendo possível sair do planeta, quando se viaja para os pólos geográficos. A abertura do copo que está no sentido para cima, outro indício de que o discente despreza a interação gravitacional entre o objeto e a Terra. Há uma análise ingênua cientificamente, estando a Terra isolada, em que não interage gravitacionalmente com corpos. Um aluno apresentou sua resposta categorizada no N1:

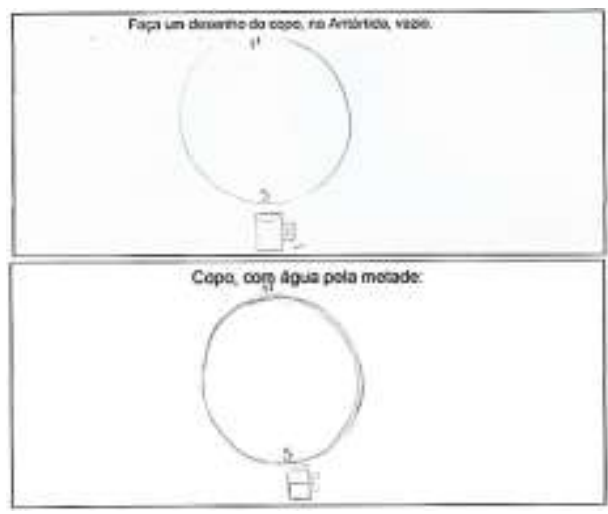

Figura 4: Resposta do Aluno A18 categorizada no N1.

As respostas categorizadas como Nível 2 (N2) percebemos que há a concepção de Terra esférica, mas sem associação com o campo gravitacional terrestre. Por vezes indicaram haver uma ideia de um limite inferior para o planeta, impossibilitando os objetos de caírem no espaço cósmico. Vinte e nove alunos apresentaram respostas neste nível, como as do Aluno A28, na Figura 5:

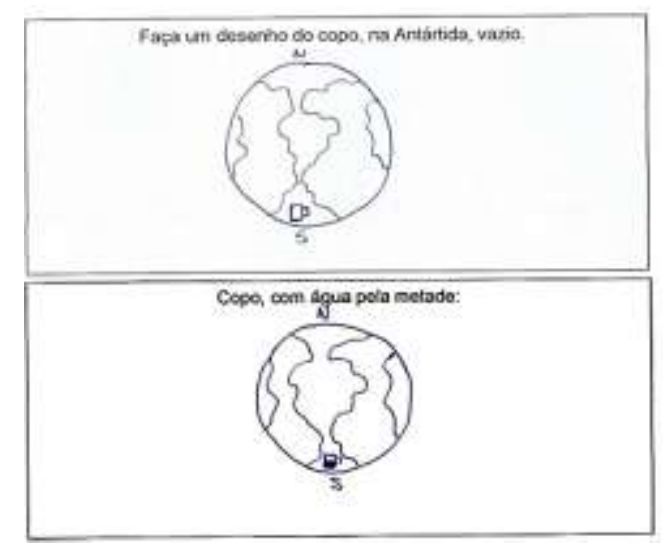

Figura 5: Resposta do Aluno A28 categorizada no N2.

A quinta questão, de múltipla escolha, apresentava o sistema Sol-Terra e abordou conceitos relacionados com a trajetória de revolução da Terra, dentro deste sistema, conforme Figura 6 : 


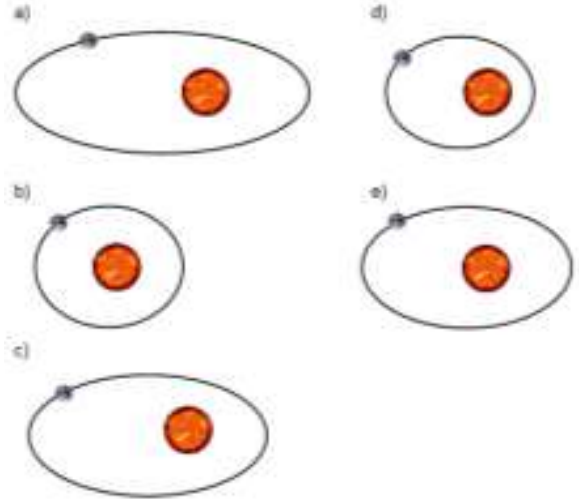

Figura 6: Opções de respostas pertencentes à quinta questão.

Conforme Figura 6 a resposta adequadamente científica é que apresenta menor valor de excentricidade da trajetória de revolução da Terra ao redor do Sol. A Figura 7 nos mostra a distribuição de opções escolhidas pelos alunos nesta questão:

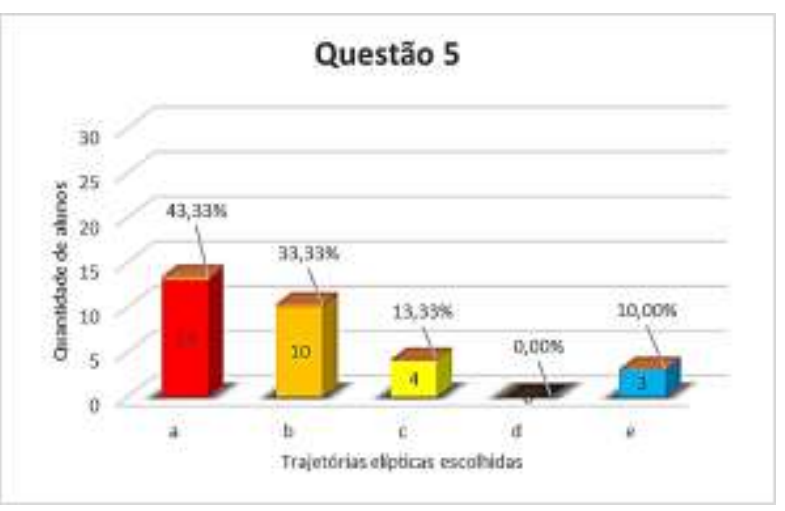

Figura 7: Respostas escolhidas dos alunos.

A alternativa "a" reflete a forma como muitos livros de Física e os de ciências da educação básica e do nível superior representam a trajetória de translação do planeta Terra ao redor do Sol. $\mathrm{Na}$ pesquisa realizada por Nascimento et al. [5,10] fica ratificado que a resposta mais coerente, conforme as opções apresentadas é a "b". Na sexta questão buscou-se investigar as concepções presentes na estrutura cognitiva dos discentes em relação à caracterização das estações do ano. Esperava-se como resposta cientificamente aceitável, o modelo de estações do ano descrito por Selles e Ferreira [11] e Nascimento et al. [5]. Estes autores caracterizam as estações conforme as regiões geográficas brasileiras: na região norte do Brasil, há estações da seca e da chuva, respectivamente chamadas de verão e inverno. Já no Sul e Sudeste, há quatro estações do ano, não da forma como ocorrem em países de clima temperado, como no Hemisfério Norte. As estações dessas regiões brasileiras são identificáveis principalmente pelas diferenças na temperatura, poucas mudanças nas paisagens e, alteração na duração do dia.

Os níveis de categorização foram do Nível 1 ao Nível 4: O nível 1 (N1) respostas que se enquadram em regiões temperadas: As quatro estações bem definidas, com mudanças na paisagem. O nível 2 (N2) traz características semelhantes ao modelo contido no nível 1 mas com alteração na estação inverno. Ao invés de neve e bonecos de neve, apenas a chuva, ainda ocorrendo mudança na paisagem. O nível 3 inclui respostas com características de apenas duas estações: o verão, que corresponde as estações das secas, e o inverno, que representa a estação das chuvas, não ocorrendo mudança na paisagem. O nível 4 corresponde ao enquadramento em que os alunos não conseguiram descrever as estações do ano. A Figura 7 descreve a quantidade de alunos em função dos níveis de concepções verificados:

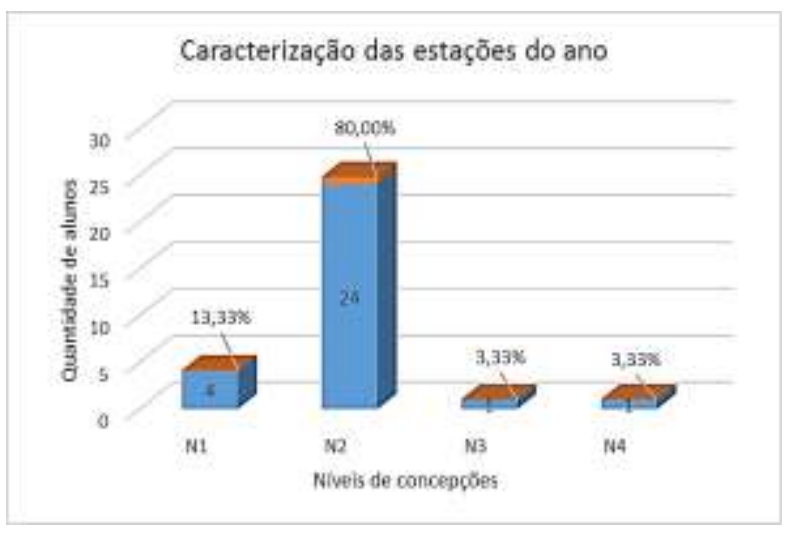

Figura 8: Respostas escolhidas dos alunos.

A maioria dos alunos (80\%) apresentaram respostas características do N2. Essa quantidade reflete o fato contido ainda em diversos materiais instrucionais do ensino de ciências, em que as estações do ano não são abordadas com características regionais do território brasileiro [11]. O que se percebeu entre os alunos participantes da pesquisa é que trouxeram concepções de um modelo de estações pertencentes aos países do Hemisfério Norte. A sétima e última questão solicitou dos alunos conhecimentos em relação a causa das estações do ano, utilizando o sistema Sol-Terra e os raios solares (insolação): a inclinação do eixo imaginário da Terra 
em relação a perpendicular do plano da órbita. $\mathrm{Na}$ Figura 10 a distribuição de respostas dos alunos da sétima questão:

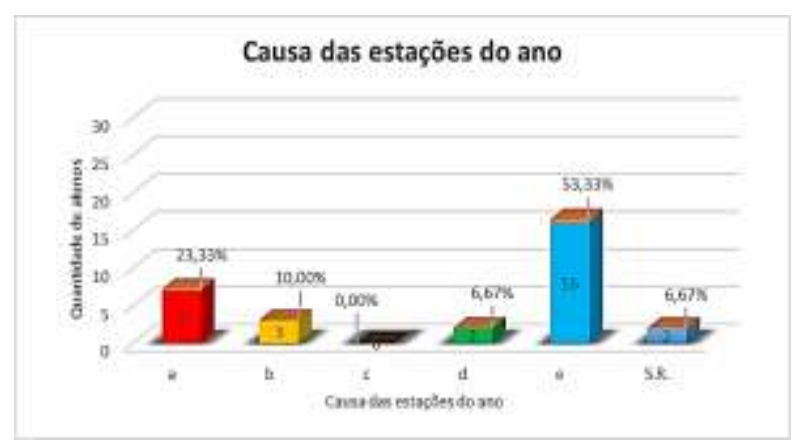

Figura 9: Escolhas de repostas pelos alunos.

Sabe-se que a ocorrência das estações do ano é consequência combinada do movimento de translação e é da inclinação do eixo de rotação da Terra, de aproximadamente $23,5^{\circ}$ em relação à normal ao plano descrito por sua órbita em torno do Sol, o que altera a inclinação dos raios solares em cada uma das regiões da Terra ao longo do ano [12]. Apenas 7 alunos apresentaram conhecimentos em relação a causa das estações do ano explorada na questão.

\section{Considerações finais}

A realização do questionário semiestruturado teve a função de investigar as concepções dos discentes quanto aos subsunçores necessários para as abordagens da temática de Terra como corpo cósmico. Para Ausubel uma das condições para que ocorra a aprendizagem significativa é justamente esta: a presença de conhecimentos prévios específicos na estrutura cognitiva do aprendiz, para que seja apresentado a ele o material de aprendizagem. Sendo assim, verificou-se que, poucos alunos dispunham de algum conhecimento prévio necessário para a aprendizagem dos fenômenos astronômicos, como por exemplo, as estações do ano.

\section{Agradecimentos}

Jefferson Nascimento agradece à FAPESB por meio do apoio financeiro parcial recebido através da bolsa de doutorado (BOL170/2015). Marcelo A. Moret agradece ao CNPq pelo suporte financeiro parcial oriundo de sua bolsa de Produtividade em Pesquisa (No. 304454/2014-1).

\section{Referências}

[1] NASCIMENTO, J. O. do; NEIDE, I. G. ; GONZATTI, S. E. M. Objetos de Aprendizagem e o Microsoft Excel como ferramentas auxiliares no Ensino de Física. Caderno Pedagógico (Lajeado. Online), v. 13, p. 124-138, 2016.

[2] MOREIRA, Marco Antônio. 0 que é, afinal, aprendizagem significativa. Material de apoio aula inaugural do Programa de Pós-Graduação em Ensino de Ciências Naturais. UFMG, Cuiabá, MT, 2010. Disponível em $<$ http://www.if.ufrgs.br/ moreira/oqueeafinal.pdf>. Acesso em: 19 mar. 2014

[3] NASCIMENTO, J. O. do; NEIDE, I. G. ; GONZATTI, S. E. $M$. Modelagem e simulação computacional no ensino de Física: Uma proposta de estudo de caso com o PROEJA. In: XXI Simpósio Nacional de Ensino de Física, 2015, Uberlândia/MG. Anais do XXI SNEF, 2015. v. 1. p. 1-8. Disponível em: <http://www.sbf1. sbfisica.org.br/eventos/snef/xxi/sys/resumos/T0527-2.pdf>. Acesso em: 04 mar. 2015

[4] MOREIRA, Marco Antônio. Aprendizagem significativa, organizadores prévios, mapas conceituais, diagramas $\mathrm{V}$ e unidades de ensino potencialmente significativas. Encontro Regional de Aprendizagem Significativa I ERAS NORTE. UEPA, Belém, 2013. Disponível em: <http://paginas.uepa.br/erasnorte2013/images/sampledata/figu ras/aprend_\%20signif_\%20org_prev_mapas_conc_diagr_v_e _ueps.pdf>. Acesso em: 23 abr. de 2014

[5] NASCIMENTO, J. O. do; NEIDE, I. G.; GONZATTI, S. E. M.; MORET, M. A. A modelagem e a simulação computacional como ferramentas tecnológicas no ensino de física. Revista signos, v. 38, p. 62-82, 2017.

[6] BRASIL. Ministério da Educação. Programa de Integração da Educação Profissional com a Educação Básica na Modalidade de Educação de Jovens e Adultos - PROEJA. Formação Inicial e Continuada/Ensino Médio. Documento Base, 2007.

[7] NUSSBAUM, Joseph; NOVAK, Joseph D. An assessment of children's concepts of the earth utilizing structured interviews. Science Education, v. 60, n. 4, p. 535-550, 1976.

[8] NARDI, R.; CARVALHO, A. M. P. Um Estudo sobre a Evolução das Noções de Estudantes sobre Espaço, Forma e Força Gravitacional do Planeta Terra. Investigações em Ensino de Ciências, Porto Alegre, v. 1, n. 2, p. 132-144, ago. 1996.

[9] BAXTER, J. Children's Understanding of Familiar Astronomical Events. International Journal of Science Education, London, v. 11, n. 5, p. 502-513, 1989. Special issue.

[10] NASCIMENTO, J. O. do; NEIDE, I. G.; GONZATTI, S. E. M.; MORET, M. A.; Um modelo computacional para auxiliar o ensino da temática de Terra como corpo cósmico, $p$. 128-133 . In: . São Paulo: Blucher, 2017.

ISSN 2358-2359, DOI 10.5151/phypro-viii-efa-29

[11] SELLES, S. E. e FERREIRA, M. S. Influências históricoculturais nas representações sobre as estações do ano em livros didáticos de ciências. Ciência \& Educação, v.10, n.1, p.101- 110, 2004

[12] KEPLER, S. O.; SARAIVA, M. F. O. Oliveira. Astronomia \& Astrofísica. 3. ed. São Paulo: Editora Livraria da Física, 2014. v. 1. 780p. 